\title{
L'esperança de vida lliure de malaltia no augmenta a Espanya
}

\section{Pilar Zueras, Institute for Social and Economic Research, University of Essex, i Centre d'Estudis Demogràfics i Elisenda} Rentería, Centre d'Estudis Demogràfics

La COVID-19 ha suposat una aturada en la contínua progressió de l'esperança de vida en néixer, que a Espanya es situava entre les més altes del món. Malgrat que el seu efecte depressiu sigui conjuntural, ja que s'espera que millori de forma ràpida els propers anys, ens ha fet reflexionar sobre l'evolució prèvia a la pandèmia. És cert que l'augment dels anys de vida ha estat progressiu i continuat, però en els darrers anys aquests guanys no s'han traduït en millores a la salut entre la població gran. Tot i que l'esperança de vida lliure de discapacitats als 65 anys ha estat molt estable en el temps, els resultats són menys encoratjadors quan es considera la presència de malalties i condicions cròniques. En aquest número del Perspectives Demogràfiques investiguem si s'han guanyat o perdut anys de vida lliures de malalties a l'edat de 65 anys entre el anys 2006, 2012 i 2017 pels homes i dones a Espanya i per comunitats autònomes (CCAA). Els resultats indiquen que, malgrat l'augment en anys d'esperança de vida, també augmenta el temps que les persones viurem amb malalties diagnosticades si no es reverteix la tendència actual. Entre les malalties i condicions més freqüents hi ha la hipertensió, el mal d'esquena crònic, la diabetis i les malalties del cor. Les diferències entre homes i dones tendeixen a convergir en anys de vida passats en bona salut com a conseqüència, principalment, de l'allargament dels anys de vida viscuts en mala salut entre els homes.

\section{L'ESPERANÇA DE VIDA I L'INCREMENT DEL TEMPS VISCUT AMB MALALTIES}

L’esperança de vida a Espanya està actualment entre les més altes del món amb 80,9 anys pels homes i 86,2 anys per les dones al 2019. Aquest creixement positiu s'ha observat sense interrupcions des de la dècada dels 70 del segle passat. Cal preguntar-se, però, si aquests guanys de vida han estat també en bona salut, especialment entre les persones més grans. Segons les dades de l'Institut Nacional d'Estadística (INE), l'esperança de vida en bona salut al néixer ha augmentat durant els darrers 15 anys. En canvi, els anys viscuts en bona salut a partir dels 65 anys, s'han mantingut força estables malgrat el creixement en l'esperança de vida (INE, 2020). La mesura més comuna per definir bona salut es basa en l'absència de limitacions funcionals o discapacitats. Amb tot, és important saber què passa amb altres indicadors de salut, com per exemple, conèixer quant de temps de les nostres vides passarem amb malalties

FIGURA 1. Evolució de l'esperança de vida als 65 anys $i$ dels anys viscuts amb i sense malaltia
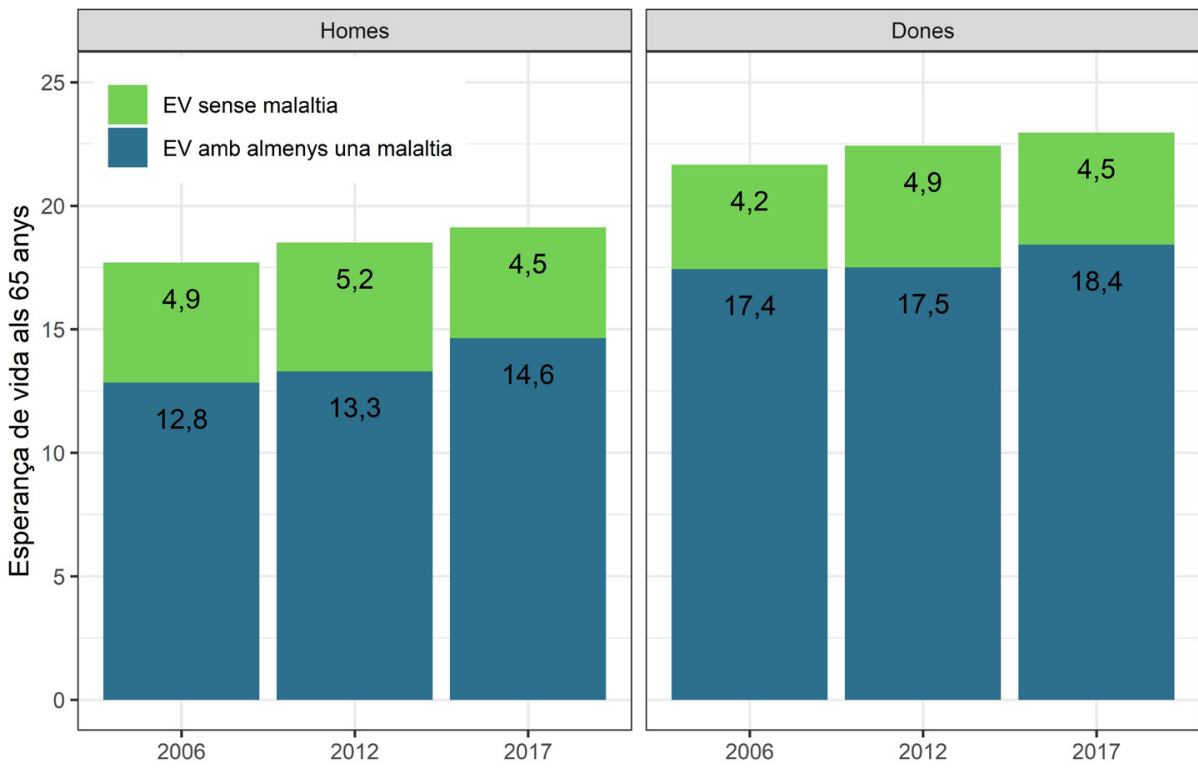

Font: INE i ENSE 2006, 2012, 2017 cròniques o condicions adverses de salut. Aquesta perspectiva resulta rellevant perquè les malalties cròniques són un fort determinant de la qualitat de vida de les persones i estan relacionades amb molts problemes de salut, augmenten el risc de morir més jove i defineixen les necessitats sanitàries de la població, determinant el nivell d'utilització i el tipus d'intervencions que es realitzen als serveis de salut.

Els augments d'esperança de vida es deriven de millores que endarrereixen la mort de les persones. Si alhora que es posposa la mort, l'edat en que comencen les malalties o problemes de salut no varia, es produeix el que s'anomena una 
extensió de la morbiditat, on passem a viure més anys en mala salut. Però si l'edat en aparèixer la malaltia s'endarrereix, poden ocórrer dues coses. Per una part, si aquesta edat augmenta més lentament quel'esperança devida resultaria, denou, enl'extensió de la morbiditat. En canvi, si l'edat d'inici d'algun problema de salut s'endarrereix més ràpidament que el creixement de l'esperança de vida, provocaria una compressió de la morbiditat, que es concentraria més en els darrers anys de vida. Les dades de les enquestes nacionals de salut combinades amb les dades de mortalitat per edat ens permeten investigar si hi ha hagut compressió o expansió de la morbiditat a Espanya en els darrers anys, és a dir, si el temps de vida amb mala salut ha augmentat o ha disminuït. Així doncs, calculem el temps d'esperança de vida a partir dels 65 anys que vivim a Espanya amb alguna malaltia crònica o condició de salut i si es distribueix de manera diferent en les CCAA. Donades les diferències en mortalitat i morbiditat entre sexes, analitzem la seva recent evolució separadament per homes i dones. Fem servir les dades de les enquestes nacionals de salut de 2006, 2012 i 2017, on investiguem la presència de diversos problemes de salut com asma, càncer, diabetis, ictus, hipertensió, infart de miocardi, malaltia del cor, malaltia obstructiva pulmonar crònica (MPOC) i mal d'esquena crònic - recordant que la majoria d'elles està relacionada amb la mortalitat per COVID-19. Utilitzem el mètode anomenat de Sullivan que es basa en aplicar les proporcions d'individus que tenen una de les malalties escollides a una taula de vida. El càlcul, basat en les observacions específiques per sexe i grups d'edat quinquennal de la presència de malaltia i les defuncions, permet obtenir el temps de l'esperança de vida (a partir d'una determinada edat) viscut amb cadascuna de les condicions, amb almenys una d'elles o sense cap d'elles.

La Figura 1 mostra l'evolució de l'esperança de vida als 65 anys per homes i dones entre 2006 i 2017 conjuntament amb l'evolució de l'esperança de vida a aquesta mateixa edat amb almenys alguna de les malalties especificades. L'esperança de vida mostra un creixement lineal passant de 17,7 a 19,1 anys pels homes i de 21,7 a 23,0 anys per les dones. Al mateix temps, el nombre d'anys viscuts sense malaltia ha per sexe

Font: INE i ENSE 2006, 2012, 2017 tingut una evolució més estable. Augmenta lleugerament entre 2006 i 2012 i torna a disminuir entre 2012 i 2017, però mantenint-se sempre al voltant dels 5 anys pels homes i lleugerament inferior per les dones. Complementàriament, els anys viscuts amb alguna malaltia han augmentat a un ritme més lent entre 2006 i 2012 però han mostrat un increment més gran entre 2012 i 2017, especialment entre els homes. Pel que fa a les diferències per sexe, les dones presenten, de forma consistent, una esperança de vida superior als homes en tots els anys. Però quan observem l'evolució dels anys viscuts en bona salut, es constata que hi ha hagut una convergència entre els dos sexes, on al 2006 els homes vivien més anys sense cap d'aquestes malalties, però al 2017, aquest temps viscut en bona salut s'equipara al de les dones. De tota manera, com que les dones tenen una esperança de vida superior als homes, el temps viscut amb malaltia és també més llarg per a elles durant tot el període. Tot i els anys de vida guanyats entre 2006 i 2017, 1,3 pels homes i 1,4 per les dones, ells han perdut 0,4 anys lliures de malaltia (-26,7\% de l'augment de l'esperança de vida) i elles han guanyat 0,3 anys (23,9\% del seu guany). Però l'impacte i l'evolució de les malalties no ha estat igual per a homes i dones.

\section{LES DIFERÈNCIES DEGĖNERE EN ELTEMPS VISCUT AMB CADA MALALTIA}

Aquest estudi inclou nou condicions de salut que són especialment rellevants per diferent motius. El càncer i les malalties cerebrovasculars i cardiovasculars (ictus, infart de miocardi i altres malalties del cor) estaven entre les cinc principals causes de mort a Espanya durant el període analitzat. A més, hem considerat

FIGURA 2. Evolució de la proporció de l'esperança de vida als 65 anys viscuda amb cada malaltia

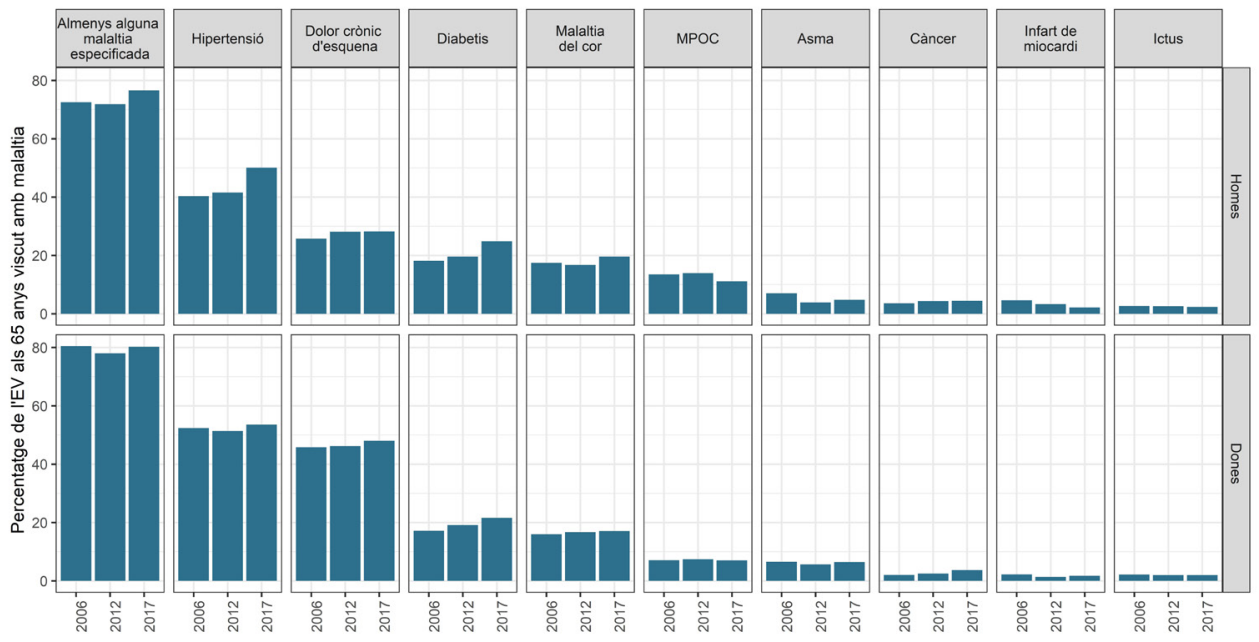


dos afeccions de salut que són factors de risc cardiovascular: hipertensió i diabetis. Hem inclòs el mal d'esquena (dolor lumbar i cervical crònics), que va ser el principal factor associat als anys de vida viscuts amb discapacitat a Espanya el 2016. Finalment, també hem examinat l'asma i la malaltia pulmonar obstructiva crònica (MPOC), les dues malalties respiratòries més freqüents. Sha descartat, per contra, incloure el colesterol alt ja que part de l'augment observat és conseqüència del canvi de paràmetres de diagnòstic entre les diferents enquestes. Tampoc s'han pogut incloure altres malalties que causen deteriorament funcional (com l'artrosi) per manca de comparabilitat entre les enquestes. Algunes d'aquestes condicions de salut preses en compte, no només són principals causes de mortalitat $\mathrm{i}$ càrrega de malaltia i discapacitat, sinó també factors de risc associats a la gravetat i l'ingrés hospitalari en cas de COVID-19.

Quan analitzem cadascuna de les malalties i condicions de salut per separat, podem veure a la Figura 2 quines són les que més impacten en el temps viscut amb mala salut i si hi ha diferències per raó de sexe. Tenir hipertensió és la condició de salut més comuna, on els homes de més de 65 anys vivien 9,6 anys amb ella al 2017 i 12,3 anys les dones, el que representa $53,6 \%$ i 50,1\% del temps que els queda per viure als homes i les dones, respectivament. Tenir dolor d'esquena crònic és la següent condició més prevalent, especialment per les dones, representant $28,2 \%$ de l'esperança de vida als 65 anys dels homes i 48,0\% de les dones al 2017.

En moltes de les malalties podem observar un augment sostingut del temps d'esperança de vida viscut amb la malaltia (hipertensió només pels homes, malaltia del cor només per les dones i dolor crònic d'esquena, diabetis i càncer pels homes $\mathrm{i}$ les dones), però aquest augment ha estat especialment significatiu per tenir hipertensió i diabetis entre els homes. L'evolució ha estat diferent per altres malalties (asma per homes i dones, malaltia del cor per homes i hipertensió i infart de miocardi per dones) per les quals la proporció de temps viscut amb malaltia s'ha reduït o mantingut entre 2006 i 2012 però ha augmentat entre 2012 i 2017. En el cas de la MPOC, ha augmentat al 2012 i ha disminuit al 2017 tant per homes com per dones. I per últim, algunes malalties han disminuït la seva proporció de temps de vida viscut amb elles entre 2006 i 2017 (ictus tant pels homes com per les dones i, pels homes, també infart de miocardi). Tant en el cas d'aquestes últimes condicions de salut com en la MPOC, s'observa una compressió de la morbiditat.

\section{EVOLUCIÓ I HETEROGENEÏTAT ENTRE CCAA: CREUAMENT DE TRAJECTÒRIES ENTRE HOMES I DONES}

Tant l'esperança de vida com els anys viscuts amb bona o mala salut presenten variabilitat a nivell de CCAA. A la Figura 3 es pot veure la distribució dels diferents indicadors entre les 17 CCAA estudiades separades per sexe i any. L'esperança de vida presenta una evolució més consistent i menys variació entre regions, mostrant un augment progressiu a tot arreu. Pel que fa a l'esperança de vida amb almenys una malaltia i l'esperança de vida sense malalties, l'heterogeneïtat està present a tots els anys, sent inferior al 2012 pels homes i al 2006 per les dones, però en els dos casos, 2017 sembla l'any on les diferències entre CCAA han augmentat en major mesura. Aquest augment de l'heterogeneïtat de l'esperança de vida als 65 anys amb alguna malaltia durant el 2017 es reflecteix en una diferència de valors entre les CCAA de 5,2 anys pels homes i 5,4 anys per les dones, mentre que al 2006 la diferència era de només 4,0 anys pels homes i 3,3 anys entre

FIGURA 3. Heterogeneïtat regional dels canvis en els anys d'esperança de vida als 65 anys

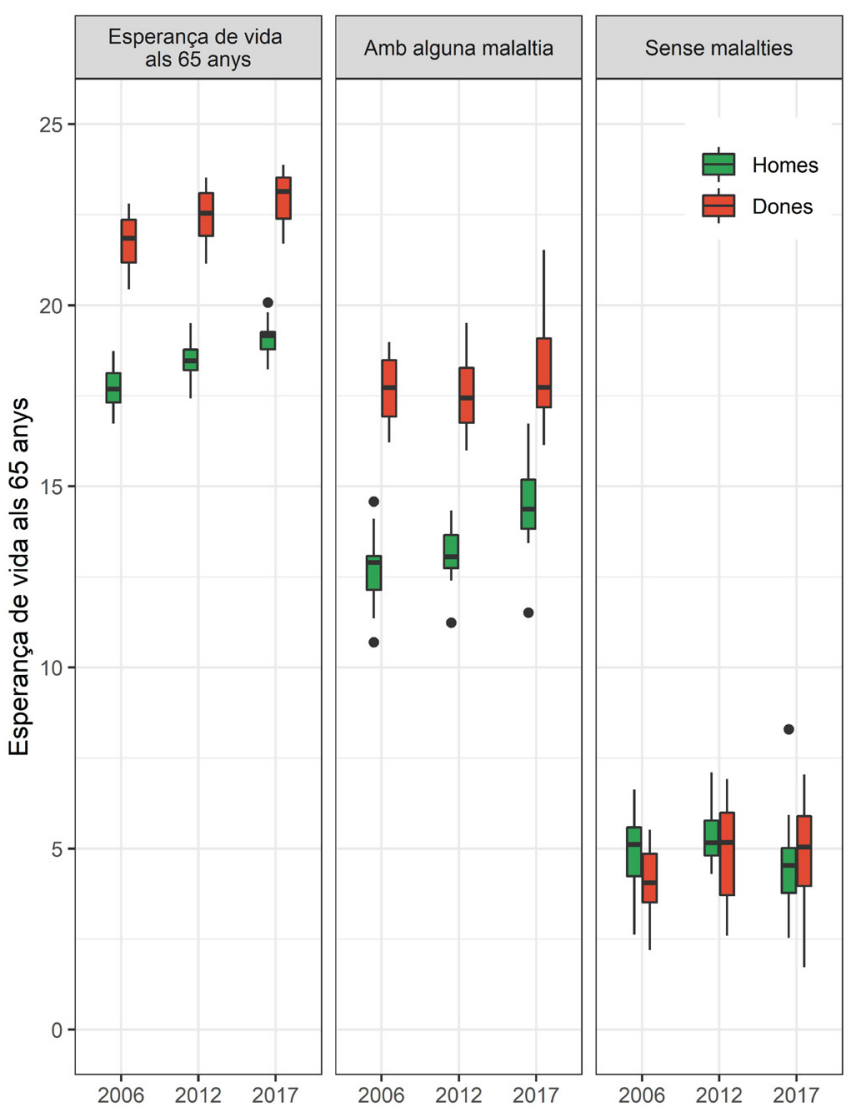

Font: INE i ENSE 2006, 2012, 2017

Nota: S'inclouen totes les CCAA excepte les Ciutats Autònomes Ceuta i Melilla 
les dones. En moltes CCAA, degut a l'estancament i lleugera disminució del temps viscut sense malalties, especialment entre els homes, hi ha hagut un augment del número d'anys viscuts amb alguna malaltia entre el $2006 \mathrm{i}$ 2017. Pel que fa als anys viscuts en bona salut, l'evolució convergent entre sexes porta a que al 2017 les dones equiparin o avantatgin els homes a la majoria de CCAA, reproduint els resultats a nivell nacional.

\section{LA COMPRESSIÓ DE LA MORBIDITAT: UN OBJECTIU PRIORITARI}

Revertir la tendència a acompanyar l'allargament de l'esperança de vida a les edats més avançades amb un estancament dels anys viscuts en bona salut ha de ser un objectiu prioritari del Sistema de Salut en els propers anys. A partir dels 65 anys, la presència de malalties i problemes de salut no ha disminuït des de l'any 2006, el que ha provocat un augment en el anys de vida viscuts en mala salut, especialment pels homes. Tenir hipertensió, mal d'esquena crònic, diabetis i malalties del cor són les condicions més comuns per homes i dones. I, per la gran majoria de malalties i condicions considerades, s'ha observat un augment o estancament del temps viscut amb elles. A més, aquest estancament en la millora dels anys viscuts en bona salut ha estat més pronunciat entre $2012 \mathrm{i}$ 2017, període en el que també s'han ampliat les diferències entre CCAA. Existeixen factors molt diversos que expliquen aquesta tendència. Per una banda, les millores del sistema sanitari s'han centrat més en resoldre el casos més aguts, més propers a la mort, el que comporta una millora en la supervivència, però també un augment del nombre d'individus que pateixen malalties o problemes de salut. Igualment, durant els darrers anys s'ha intensificat un empitjorament de la dieta en tota la població, que, junt amb la disminució de l'activitat física, provoquen un augment de l'índex de massa corporal (Basterra-Gortari et al., 2017). Això té, inevitablement, conseqüències negatives en la prevalença de malalties $i$ condicions de salut com la hipertensió, la diabetis, malalties del cor, ictus i càncer. De totes formes, aquestes tendències no s'han produït de forma similar en el territori, el que fa pensar que es poden implementar polítiques que ajudin a millorar la salut de les persones d'edat avançada. A més, existeixen importants diferències entre homes i dones, destacant que, durant els darrers anys, ells han patit un estancament de la seva salut més pronunciat que elles. Aquesta evolució més desfavorable pels homes que per les dones podria estar darrera de l'aparent paradoxa de la major incidència de severitat i fatalitat per COVID-19 entre la població masculina. Elles estan més exposades a la infecció per la seva dedicació al treball de cura, major presència en el sector sanitari i la pròpia feminització de la vellesa. No obstant això, el major desequilibri en la cronificació de les malalties i la mala salut que acompanya els guanys de vida en els homes que trobem en aquest estudi permet entendre, en part, la major mortalitat per COVID-19 entre els homes que entre les dones.
Referències bibliogràfiques

Basterra-Gortari, F. J.; Bes-Rastrollo, M.; Ruiz-Canela, M.; Gea, A.; MartinezGonzález, M. Á. (2017) "Prevalence of obesity and diabetes in Spanish adults 1987-2012". Medicina Clínica: 148 (6): 250-256 (DOI: $10.1016 /$ j.medcli.2016.11.022).

INE (2020) Mujeres y Hombres en España, 2020. Salud. 4.2. Esperanza de vida en buena salud [Internet]. 2020 [citado 15 de diciembre de 2020]. Enllaç

Soriano,, J. B.; Rojas-Rueda, D.; Alonso, J.; Antó, J. M.; Cardona, P.-J.; Fernández, E. et al. (2018) "La carga de enfermedad en España: resultados del Estudio de la Carga Global de las Enfermedades 2016". Medicina Clínica: 151 (5): 171-190 (DOI: 10.1016/j.medcli.2018.05.011)

Zueras P.; Rentería, E. (2020) “Trends in disease-free life expectancy at age 65 in Spain: Diverging patterns by sex, region and disease". PLOS ONE, 15 (11): e0240923 (DOI: 10.1371/journal. pone.0240923).

\section{Citc}

Zueras, P. i Rentería, E. (2021) "L'esperança de vida lliure de malaltia no augmenta a Espanya". Perspectives Demogràfiques, 22: 1-4 (ISSN: 26964228). DOI: 10.46710/ced. pd.cat.22.

\section{ISSN}

ISSN 2696-4228

DO

https://doi.org/10.46710/ced.pd.cat.22 Editors

Andreu Domingo i Albert Esteve (Centre d'Estudis Demogràfics)

Correspondència dirigida a

Pilar Zueras

pzueras@ced.uab.es

Elisenda Rentería

erenteria@ced.uab.es

\section{Agraïments}

Agraïm el finançament de l'Economic and Social Research Council (UK) Research Center on Micro-Social Change de la University of Essex (ES/So12486/1), del Plan Estatal de Investigación Científica y Técnica y de Innovación 2013- 2016. Programa Estatal de Promoción del Talento y su Empleabilida, Subprograma Estatal de Formación y en el Subprograma Estatal de Incorporación: Ayudas para Contratos Ramón y Cajal 2017 (RYC2017-22586) i del projecte 'HEALIN' (ERC-2019- CoG-GA No 864616)

Crèdits

Gràfics: Anna Turu

Maquetació: Xavier Ruiz Vilchez

Enllaç url

https://ced.uab.cat/difusio/butlletiperspectives-demografiques/

\section{Contacte}

Centre d'Estudis Demogràfics. Carrer de Ca n'Altayó, Edifici E2 Universitat Autònoma de Barcelona 08193 Bellaterra / Barcelona Espanya

Telèfon: +34 935813060

Correu:demog@ced.uab.es

Web: http://ced.uab.es/ 